\title{
LA INTERVENCIÓN DE LOS PARLAMENTOS NACIONALES DE LOS ESTADOS MIEMBROS DE LA UE EN EL CONTROL DE SUBSIDIARIEDAD Y EN EL DE PROPORCIONALIDAD. ANTECEDENTES E IMPLEMENTACIÓN: DE LA DÉCADA DE LOS NOVENTA A LA PRIMERA DÉCADA DEL SIGLO XXI
}

\author{
Maria Rosa RiPOLLÉS SERRANO \\ Letrada de las Cortes Generales \\ Departamento de Derecho Constitucional \\ Facultad de Derecho \\ Universidad Complutense de Madrid \\ mripol01@ucm.es
}

\begin{abstract}
RESUMEN
Este trabajo es una sintesis del texto de unas conferencias impartidas en la Facultad de Ciencas Politicas de la UCM (Campus Somosaguas) en el Seminario sobre Unión Europea, a lo largo de diferentes cursos académicos. Se ha realizado sobre documentos COM, información de la COSAC e informes de los letrados de la CMUE. En él se aborda el significado de la intervención de los Parlamentos nacionales de los Estados miembros de la Unión Europea en la legislación europea a través de los principios de subsidiariedad y proporcionalidad y su primera practica en España durante los años noventa del siglo XX, con mención específica del papel y procedimiento de la CMUE de las Cortes Generales.
\end{abstract}

Palabras clave: control parlamentario UE, principio de subsidiariedad y de proporcionalidad, relaciones Estados miembros-UE, iniciativas legislativas europeas, cooperación parlamentos nacionales, instituciones UE, Comisión Mixta de la Unión Europea.

\section{ABSTRACT}

This piece of work is a summary of the text from some lectures which took place at the Political Science Faculty of Complutense University (Somosaguas campus) at a Seminar on the EU, throughout the academic years. It has been drawn on COM docs, and information on COSAC together with the reports of the clerks from EU Military Committee (EUMC). It deals with the meaning of intervention of National Parliaments of EU members in European laws by means of subsidiarity and proportionality principles and their put into practice for the first time throughout 1990s, specially looking into the role and procedure of EUMC by Parliament.

Keywords: Control of EU Parliament, Subsidiary and proportion principles, EU members relationships. EU, European Law Initiatives, National Parliament Cooperation, EU institutions, EU Joint Commision. 


\section{ZUSSAMENFASSUNG}

Die vorliegende Arbeit ist eine Zusammenstellung von Vortragstexten, die an der Fakultät für Politikwissenschaften der Universität Complutense von Madrid (Campus Somosaguas) im Seminar über die EU, über verschiedene akademische Kurse hinweg gehalten wurden. Diese beschäftigten Sie mit den Dokumenten COM,Informationen der Konferenz der Europaausschüsse (COSAC) sowie Berichte der Anwälte des Europäischen Militärausschusses (CMUE). In diesen Vorträgen wird die Bedeutung der Intervention der nationalen Parlamente der EU-Mitgliedsstaaten, durch das Prinzip der Subsidiarität und Proportionalität, und die erste praktische Ausfübrung in Spanien im letzten Jabrzebnt des 20. Jabrbunderts behandelt. Eine besondere Erwäbnung findet hierbei die Rolle und die Vorgehensweise des CMUE und des Spanischen Parlaments.

Schlüsselwörter: Parlamentarische Kontrolle EU, Subsidiaritätsprinzip und Proportionalitätsprinzip, Beziehungen der EU-Mitgliedsstaaten, EU- Gesetzesinitiativen, nationale parlamentarische Kooperation, EU-Institutionen, Gemischter EU-Ausschuss.

SUMARIO: I. LA ALERTA TEMPRANA EN EL TRATADO DE LISBOA.II. LA EXPERIENCIA EN LOS DIFERENTES PAÍSES COMUNITARIOS- III. LA EXPERIENCIA ESPAÑOLA.

\section{LA ALERTA TEMPRANA EN EL TRATADO DE LISBOA}

El Tratado Constitutivo de la Unión Europea (en adelante, TCE) contiene en su art. 5, en los términos incorporados por el Tratado de Maastrich, el principio de subsidiariedad, que supone que «en los ámbitos que no sean competencia exclusiva, la Comunidad intervendrá, conforme al principio de subsidiariedad, solo en la medida en que los objetivos de la acción pretendida no puedan ser alcanzados de manera suficiente por los Estados miembros».

El Tratado de la Unión Europea (en adelante, TUE) se refiere en dos ocasiones al principio de subsidiariedad (en adelante, PS): para ilustrar el sentido del mismo, con la idea de que «las decisiones serán tomadas de la forma mas próxima a los ciudadanos que sea posible» (art. 1, antes A), y para señalar que «los objetivos de la Unión se alcanzarán en el respeto del principio de subsidiariedad» (art. 2, antes B).

Parece evidente que la finalidad política del PS es constreñir las competencias de la Unión Europea a las exclusivas, evitando el efecto expansivo, a la par que se asocian los Parlamentos nacionales a las instancias legislativas europeas, creando un tejido concordante que favorezca la común cultura política europea. 
El Tratado de Ámsterdam añadió un protocolo sobre la aplicación del PS, y el Parlamento, el Consejo y la Comisión adoptaron sobre ello un acuerdo institucional el 25 de octubre de 1993.

El TUE, en la redacción dada por el Tratado de Lisboa, reproduce el art. I-XI del Tratado Constitucional, que preveía la intervención de la Unión en los ámbitos que no sean de su exclusiva competencia, «solo en el caso de que y en la medida en que» los objetivos de la acción pretendida no puedan ser alcanzados de manera suficiente por los Estados miembros ni a nivel central ni a nivel regional o local, sino que puedan alcanzarse mejor debido a la dimensión o a los efectos de la acción pretendida a escala de la Unión; esto es, el PS solo es aplicable respecto de competencias compartidas.

La jurisprudencia del Tribunal de Justicia de las Comunidades Europeas (en adelante, TJCE) ha constatado que el PS solo ha beneficiado a la Comunidad, aunque con el tiempo se ha observado cierto cambio en dicha jurisprudencia de modo que existe una jurisprudencia consolidada que señala que el juez comunitario ha de controlar la legalidad de los actos comunitarios a la luz de la Sentencia del Tribunal de Primera Instancia de las Comunidades de 12 de julio de 2006, caso Ayadi c. el Consejo.

Los criterios de la jurisprudencia para examinar el PS se sustentan en dos juicios: determinar si la competencia es exclusiva (siendo esta, conforme a la jurisprudencia, la política comercial común y la de conservación de los recursos pesqueros) y si el objetivo de la acción puede lograrse mejor a nivel comunitario (que el asunto que se presenta tenga elementos transaccionales en los que las actuaciones de los Estados miembros, en ausencia de regulación comunitaria, entrarían en conflicto con los requisitos de los Tratados o con los intereses de los Estados miembros, o que la actuación comunitaria proporcionaría claros beneficios debido a su escala o a sus efectos).

¿Cuáles son los antecedentes comunitarios de estos nuevos principios?

1. Ya desde Maastrich, en 1992, estaba sobre la mesa aumentar la participación de los Parlamentos nacionales por varias razones, entre ellas, desde tratar de evitar recelos soberanos o participativos por aquellos órganos que asumen la representación en el ámbito de los Estados miembros, aspecto que se agrava conforme se comienza a afectar a las competencias que forman el núcleo duro de la soberanía — política exterior, seguridad, justicia etc.- hasta añadir un mayor nivel democrático a la propia Unión Europea, en tanto en cuanto se asocia a su competencia normativa a nuevos sujetos nacionales y representativos. 
Una primera respuesta para esta participación fue la facilitación en el ámbito nacional del control parlamentario sobre los Gobiernos en esta materia - declaración aneja a Maastricht relativa al cometido de los Parlamentos nacionales en la UE o Conferencia de Parlamentos-.

2. A destacar otras formas participativas desde los Parlamentos nacionales, tales como el precedente pionero del folketing danés y después del resto de países escandinavos, consistente en el debate parlamentario previo de los asuntos mas relevantes incluidos en el orden del día de los Consejos de la UE, o, en otro orden de cosas, el sistema de sesudos estudios del Parlamento británico, o bien la reflexión previa a las modificaciones normativas-constitucionales, legales o reglamentarias en Estados miembro de carácter compuesto.

3. El Tratado de Ámsterdam en 1997 dio un paso nuevo al establecer (Protocolo sobre el papel de los Parlamentos nacionales en la UE) actuaciones de carácter vinculante en el proceso decisorio de la UE, siendo la más relevante el plazo, salvo urgencia, de seis semanas durante el cual, desde la remisión de una propuesta legislativa, el Consejo no podía deliberar sobre ella, de modo que durante dicho plazo los Parlamentos nacionales podrían estudiarla y debatirla.

4. Como es sabido, el fallido Tratado Constitucional incorporaba dos Protocolos sobre el papel de los Parlamentos nacionales en la UE y sobre aplicación de los principios de subsidiariedad y proporcionalidad, que plasmó en la denominada «alerta temprana», procedente de las aportaciones del grupo de trabajo 1 de la Convención Giscardiana sobre el futuro de Europa —encargado del PS— dirigido por el español Méndez de Vigo, retomando el originario protocolo de Ámsterdam en su vertiente de control político previo por los Parlamentos nacionales sobre el cumplimiento del PS respecto de las iniciativas legislativas de la Unión Europea.

El sistema consistía en abrir la posibilidad de que los Parlamentos nacionales, en el plazo de seis meses desde la remisión por la Comisión Europea de sus propuestas legislativas, pudieran emitir dictámenes motivados dirigidos al Parlamento Europeo (Consejo y Comisión), de manera que si el numero de tales mensajes fuera limitado - sin que se especificara quorum - la Comisión debería motivar con mas detalle y de manera concreta el acto, mientras que si un tercio de los Parlamentos nacionales emitieran dictamen, la Comisión debería revisar su propuesta y mantener, modificar o retirar la iniciativa. 
5. Este sistema del fallido Tratado por el que instituía una Constitución para Europa fue prácticamente reproducido por el Tratado de Lisboa y ha dado lugar a lo que se denomina «sistema de alerta temprana».

El art. 3 del Protocolo anejo al Tratado de Lisboa sobre aplicación de los principios de subsidiariedad y proporcionalidad establece:

«A los efectos del presente Protocolo, se entenderá por "proyecto de acto legislativo europeo" las propuestas de la Comisión, las iniciativas de un grupo de Estados miembros, las iniciativas del Parlamento Europeo, las peticiones del Tribunal de Justicia, las recomendaciones del Banco Central Europeo y las peticiones del Banco Europeo de Inversiones destinadas a la adopción de un acto legislativo».

En suma, se ha ampliado el elenco de actos sometidos a escrutinio, comprendiendo todos aquellos a los que la normativa europea les faculta para iniciar un procedimiento legislativo.

Una cuestión conexa es si el procedimiento de aplicación de la alerta temprana afecta a los proyectos al comienzo de la iniciativa o si también afecta a las posibles modificaciones posteriores. En principio, en la Convención se vio este asunto y se entendió que la iniciativa afectaba al PS, mientras que la posible modificación posterior ya quedaría en la esfera del principio de proporcionalidad. En el caso de que hubiera modificaciones que supusieran un cambio del ámbito material de la iniciativa estaría justificada la posibilidad de que los Parlamentos nacionales pudiesen emitir nuevo dictamen; ahora bien, esto tiene una clara dificultad en el procedimiento porque se necesitaría abrir nuevo plazo en el momento de la convocatoria del comité de conciliación, y la brevedad desde la convocatoria a la celebración — como máximo seis semanas - retrasaría el procedimiento, por lo que hay que sostener que, salvo casos excepcionales valorados por las instituciones legislativas de la Unión, el procedimiento de alerta temprana solo resulta aplicable al comienzo del proceso legislativo.

En cuanto al ámbito material, solo afecta a las propuestas o proyectos de actos legislativos stricto sensu, lo que excluye la PESC.

El procedimiento es el siguiente: la institución autora —Comisión, Parlamento Europeo, Consejo (cuando se trata de iniciativas de un grupo de Estados), TJCE, BCE o BEI- remite sus propuestas legislativas a la vez al legislador de la Unión y a los de los Estados miembros en la lengua correspondiente a cada Estado, con inclusión de la motivación del acto en relación con los principios de subsidiariedad y proporcionalidad, a cuyo fin ha 
de incluir una ficha que contenga: elementos para evaluar el impacto financiero; los efectos de la normativa que han de desarrollar los Estados miembros (cuando se trate de una directiva estos efectos deben comprender los relativos a la legislación regional); las razones que sustentan que un objetivo de la Unión puede alcanzarse mejor a este nivel, con indicadores cualitativos y, en su caso, cuantitativos (núcleo duro del examen de subsidiariedad), explicitando que la carga económica y administrativa a todos los niveles territoriales, agentes económicos y ciudadanos sea lo mas reducida posible («principio de intervención mínima»), e incluir el principio de proporcionalidad, esto es verificar hasta dónde puede llegar la intensidad de la regulación.

El papel de los Parlamentos nacionales de los Estados miembros básicamente consiste en emitir un dictamen motivado. ¿Con qué alcance? Pues bien, la propia regulación europea da respuesta a esta cuestión sobre los siguientes parámetros:

- ¿Qué se entiende por Parlamento nacional? El art. 6 del PS dispone que este dictamen motivado corresponde tanto al Parlamento unicameral (catorce Estados de la Unión tienen Parlamentos unicamerales) o bicameral que actúe como un todo (dos votos), cuanto a cualquiera de las Cámaras en los Parlamentos bicamerales (hay trece Estados con Parlamentos bicamerales), supuesto en que cada Cámara cuenta con un voto si actúa separadamente o $1+1$.

- ¿Qué sucede en los Estados compuestos con las Cámaras regionales? Aquí funciona el principio de autonomía intraestatal, siendo tales Estados los que han ido abriendo el ámbito de las consultas, tal y como previene el art. 5 del citado Protocolo. A destacar que, en todo caso, se habla de consultas. Y así puede suceder que al dictamen estatal se acompañen los regionales o no, y que haya un envío estatal interno a las Cámaras regionales dentro del cortísimo plazo disponible o un envío automático, pero lo que es cierto y claro es que corresponde al Parlamento estatal la responsabilidad del dictamen motivado.

- ¿Cuál es el objeto del dictamen? La disconformidad (que podría ser total o parcial, esto es, solo con parte de la iniciativa o con la totalidad de la iniciativa) por cuestionamiento del cumplimiento del principio de subsidiariedad, si bien no se puede cambiar la iniciativa.

- ¿Cuál es la fundamentación del dictamen? Razones jurídicas o valoraciones políticas. 
En cuanto al procedimiento de adopción: corresponde determinarlo a cada Cámara, si bien parece que lo procedente es remitirlo por los presidentes parlamentarios, en cuanto máximos representantes de las Cámaras, al del Parlamento Europeo, Consejo de Ministros y Comisión, y en el caso de una iniciativa de Estados, del TJCE, BCE o BEI, al presidente del Consejo, quien lo remitirá al órgano que proceda. Parece procedente una primera remisión electrónica, por lo exiguo de los plazos.

Sobre el contenido del dictamen: se trataría de la identificación de la propuesta, los motivos de disconformidad, en términos más que extensos, de modo claro, ordenado y lógico y rigurosamente argumentado. En otras palabras, con exposición que permita convencer a las autoridades legisladoras de la Unión de la inidoneidad de la medida desde el PS.

Sobre los plazos y forma: el plazo para la adopción del dictamen motivado de disconformidad es de ocho semanas desde la fecha de envío a los Parlamentos nacionales y hasta la recepción por la institución comunitaria, según dispone el art. 5 del Protocolo en la redacción de Lisboa, plazo algo mas amplio que en el Tratado Constitucional.

En cuanto a los efectos: el art. 7, párrafo 1, del Protocolo se limita a recoger que las autoridades legisladoras lo «tendrán en cuenta».

La recepción del dictamen, junto con otra información, se recoge en la base europea IPEX (Interparliamentary EU Information Exchange) ponderando la relevancia de los dictámenes emitidos — número y alcance-, aunque su número no alcance la necesidad de reexaminar el proyecto conforme a los procedimientos denominados de «tarjeta amarilla» $\mathrm{y} \ll$ tarjeta naranja».

El procedimiento de «tarjeta amarilla»: implica un reexamen limitado de la iniciativa. Ya estaba en el Tratado Constitucional y supone que, cuando los dictámenes de carácter general alcancen un número de votos superior a $1 / 3$ del total de votos, que actualmente supone dieciocho votos, equivalente a nueve Estados, o bien en el caso específico de propuestas de actos legislativos relativos al tercer pilar (cooperación judicial en materia penal o cooperación judicial), catorce votos actualmente equivalentes a siete Estados, entonces el órgano autor «debe volver a estudiar la propuesta» $\mathrm{y}$ «tras ese nuevo estudio [...] decidir motivadamente si mantiene el proyecto, lo modifica o lo retira» (art. 7, párrafo final, del Protocolo), lo que supone interrumpir el procedimiento y notificarlo a los Parlamentos nacionales.

El procedimiento de tarjeta naranja: incorporado por Lisboa, se recoge en el art. 7, apartado 3, del Protocolo. En el marco del procedimiento 
legislativo ordinario, cuando los dictámenes motivados de los Parlamentos nacionales superen la mayoría simple de los votos atribuidos a dichas Cámaras (54 en total), la propuesta debe volver a estudiarse y la Comisión podrá retirarla, modificarla o mantenerla justificándolo y comunicándola, junto con los dictámenes de los Parlamentos nacionales, para que el legislador los tenga en cuenta en el procedimiento, debiendo estudiarla el legislador (Consejo y Parlamento Europeo) antes de que concluya la primera lectura, y si por mayoría del 55 por 100 de los miembros del Consejo o mayoría de los votos emitidos en el Parlamento Europeo el legislador estima que la propuesta no es compatible con el PS, se desestimará la propuesta legislativa (fórmula de equilibrio entre quienes querían tarjeta roja y quienes rechazaban estas posibles reconsideraciones).

\section{LA EXPERIENCIA EN LOS DIFERENTES PAÍSES COMUNITARIOS}

Se ha dicho (Bretal Vázquez) que en el ámbito europeo el ejercicio del control político parlamentario respecto del Gobierno nacional y también, por sus importantes poderes, el ejercicio del control indirecto sobre el Consejo Europeo tradicionalmente se lleva a cabo conforme a tres modelos ya constatados:

1. El nórdico: espacio en el que los Parlamentos nacionales delimitan con bastante rigor el campo de actuación de sus respectivos Ejecutivos en el espectro europeo, llegando casi a establecer mandatos y limitando el margen de negociación.

2. El centroeuropeo: que es el seguido en algunos países grandes en tamaño e importancia política como Alemania, Reino Unido o Francia, en los que, sin llegar al rigor de los Parlamentos escandinavos, fijan líneas generales de negociación y actuación y exigen explicaciones posteriores si el Ejecutivo no se acomoda a ellas.

3. El mediterráneo: en países del sur de Europa, donde el control es mas laxo y con frecuencia se limita a recibir información posterior (España, por ejemplo, según han manifestado autores foráneos como Andreas Maurer o internos como Pérez Tremps).

La nueva circunstancia del control de la subsidiariedad y proporcionalidad a través de la alerta temprana ha situado a los distintos Estados miembros de la Unión en la tesitura de tener que organizar los mecanis- 
mos y órganos internos para llevar a cabo esta competencia, con respuestas distintas en cada caso, relacionadas con la «personalidad» de cada país y cada Cámara.

Con carácter previo hay que reseñar [como recoge el informe de los letrados de la Comisión Mixta de la Unión Europea (en adelante, CMUE) que se sigue en este punto] que ya desde la preparación del Tratado Constitucional algunos Parlamentos iniciaron una serie de estudios, análisis y propuestas relacionados con su papel reforzado en el futuro: este fue el caso del excelente trabajo preparado por la Comisión de Asuntos Europeos de la Cámara de los Lores británica de 14 de abril de 2005, o los elaborados por el Folketing danés también por medio de su Comisión de Asuntos Europeos el 10 de diciembre de 2004, o el Parlamento finlandés el 18 de febrero de 2005, o el Informe sobre el papel de las Cortes Generales en la aplicación de los mecanismos de control del principio de subsidiariedad y del de proporcionalidad elaborado y aprobado por la Comisión Mixta para la UE el 13 de diciembre de 2007.

A destacar también la celebración de «experiencias piloto» sobre la participación parlamentaria en la alerta temprana, la primera de la cuales fue promovida por la Conferencia de los Órganos Especializados en Asuntos de la Unión (en adelante, COSAC) en la temprana fecha de 2004 u otra en la primavera de 2005 .

Todas estas reflexiones y pruebas fueron recogidas en el XIII Informe bianual sobre desarrollos en la Unión Europea de procedimientos y prácticas relativos al escrutinio parlamentario, preparado para la 43. ${ }^{a}$ reunión de la COSAC de mayo-junio de 2010 celebrada durante el semestre español en Madrid.

Los datos más relevantes que se podían extraer de estos trabajos y experimentos previos a la entrada en vigor del Tratado de Lisboa y con el de la «alerta temprana» fueron los siguientes:

- La mayoría de los estudios proponían encomendar la primera intervención parlamentaria (instrucción y debate del procedimiento) a los órganos parlamentarios especializados en materias de la UE, así dieciséis países miembros de la UE, bien solos o junto con comisiones sectoriales afectadas (caso de las Repúblicas bálticas, Alemania o Finlandia). Algún país proponía un órgano mixto intercomités ad hoc (Holanda).

- En cuanto al órgano de aprobación del dictamen, había una mayoría que proponían que fueran los Plenos (siete países, por ejemplo, 
Alemania, Holanda, Lituania, o Reino Unido) o la propia Comisión (seis países, por ejemplo, Austria, Portugal o Eslovenia).

- En los Parlamentos bicamerales se planteaba que podía haber concertación o bien autonomía decisoria (caso del planteamiento de la Cámara de los Lores británica).

- Algunas Cámaras analizaron la posibilidad de que unos ponentes preparasen la decisión de la Comisión (por ejemplo, Francia).

- Hubo casos de un análisis en fases del procedimiento completo. Es el caso de Dinamarca, en que se preveían tres fases: la primera de dos semanas en la que el Gobierno remitiría al Parlamento un informe preliminar y la Comisión de Asuntos Europeos iniciaría el análisis y envío a las comisiones sectoriales afectadas, así como apertura pública para sugerencias y peticiones ciudadanas; una segunda fase de cuatro semanas de recepción de informes más acabados del Gobierno y las comisiones sectoriales, y una tercera fase de las dos últimas semanas en que la Comisión habría de adoptar la decisión, con información a los Parlamentos nacionales que formalmente lo soliciten. En todo caso la mayoría de estudios propugnaban la información exhaustiva del Gobierno al Parlamento basada en argumentos jurídicos y políticos.

- En cuanto a los Estados compuestos, Alemania, por ejemplo, canalizaba las intervenciones a través del Bundesrat, y el informe de la Cámara de los Lores sugería un examen previo por los Parlamentos regionales de los asuntos que pudieran serles de interés con ocasión de la presentación del programa legislativo anual de la Comisión. Mas detalladamente, en cuatro Parlamentos (Austria, Portugal, Reino Unido e Italia) se preveía la consulta a los Parlamentos regionales, y, como es sabido, en el caso español estas opiniones no eran vinculantes, mientras que en tres casos - las dos Cámaras belgas y el Bundesrat - el Parlamento regional tomaba parte activa en el escrutinio si la materia quedaba dentro de sus competencias.

En cuanto a las experiencias piloto, resulta curioso que, en un principio, contaran con la negativa del Bundestag. Ya se ha dicho que comenzaron bien pronto al amparo del COSAC, siendo la primera experiencia piloto de 2004 sobre una propuesta legislativa de la Comisión relativa al tercer paquete ferroviario y la segunda sobre la propuesta de Reglamento del Consejo de reforma del previo (CE) 2201/2003 relativo a las reglas y jurisdicción aplicables en Derecho de familia, experiencia a la que respon- 
dieron nueve Cámaras en principio y, posteriormente, veintidós de hasta diecisiete Estados, de los cuales cuatro Cámaras (Bélgica, Holanda, Reino Unido y República Checa) entendieron que la iniciativa vulneraba el principio de subsidiariedad.

La mayoría de las Cámaras usaron y vienen usando en su tramitación y repuestas una herramienta clave: IPEX (Interparliamentary Exchange of information), creado provisionalmente en 2003 y que proporciona enlaces a las web de los Parlamentos nacionales y cuya página permanente se abrió en junio de 2006 (www.ipex.eu), siendo pública desde enero de 2007. Herramienta fundamental en el sistema, junto con las corresponsalías permanentes en el Parlamento Europeo. IPEX, a través de su página, proporciona información sobre el estado de las iniciativas europeas en cada Cámara de los veintisiete Estados miembros y tienen una página para cada propuesta legislativa denominada «dossier» en la que se expone de forma escueta con símbolos el estado de tramitación del escrutinio de la misma en cada uno de los Parlamentos nacionales.

De las experiencias piloto se desprendía una idea bastante correcta de algunos de los problemas de la alerta temprana, tales como: lo exiguo del plazo de seis semanas; la enorme dificultad en trazar la frontera entre el principio de subsidiariedad y el de proporcionalidad; los retrasos en la recepción de algunas versiones lingüísticas; la insuficiencia de la motivación de la Comisión Europea, y las dificultades de conocimiento y de la cooperación interparlamentaria. Parte de estas dificultades detectadas en origen se han ido resolviendo con la cooperación necesaria de la Comisión, pero otras han sido mas difíciles de afrontar, como es el encuadramiento de los informes gubernamentales y de las asambleas regionales.

A la entrada en vigor del Tratado de Lisboa el 1 de diciembre de 2009 una gran mayoría de Cámaras (cuarenta en total en los veintisiete Estados miembros, de los cuales, como ya se ha dicho, catorce son unicamerales y trece bicamerales) aprobaron normas de distinto tipo para adaptarlas a Lisboa.

Podemos distinguir tres clases de respuestas: reformas constitucionales, reformas legales y reformas reglamentarias.

Han modificado sus Constituciones: Alemania (arts. 23 LFB, para facilitar a las Cámaras la interposición del recurso de anulación ante el TJCE por infracción del principio de subsidiariedad, y 45 y 93 LFB, relativos al procedimiento interno en el seno del Bundestag) y Francia (Reforma de 2008 de los arts. 88-6 y 88-7, también sobre recurso de anulación ante TJCE por infracción del PS y sobre facultades parlamentarias relativas a 
las cláusulas de pasarela y sobre revisión simplificada de los tratados y cooperación judicial en materias civiles, respectivamente). Otros dos Estados se plantearon también la reforma constitucional: Eslovaquia y Austria.

Cinco Estados adoptaron en un primer momento leyes: Alemania (Ley relativa al ejercicio por ambas Cámaras de su responsabilidad en la integración en materias referentes a la UE, de junio de 2009, tras la STC que disponía la necesidad de esta reforma), España (Ley 24/2009), Irlanda (Ley de la Unión Europea de octubre de 2009), Holanda (reserva parlamentaria ante actos legislativos de la UE) y Reino Unido (Ley de Reforma de la de la Unión Europea de 19 de junio de 2008). Otras reformas legales se preveían en Bélgica, Italia, Polonia, Portugal y Rumania.

$\mathrm{Y}$ nueve Estados reformaron sus Reglamentos parlamentarios con amplias modificaciones, como es el caso de Suecia (dos modificaciones de la Ley Constitucional que recoge el Reglamento parlamentario), Holanda (reformas de 2009-2010 que incorpora una «Comisión especial de escrutinio de la subsidiariedad») o la Cámara de los Lores (reforma reglamentaria de 16 de marzo de 2010), y otros con reformas mas concretas, como Bélgica (art. 37 bis del Reglamento de la Cámara Baja sobre procedimiento del escrutinio), Francia (reforma de 27 de mayo de 2009 del Reglamento de la Asamblea Nacional), Grecia (reforma que creó un nuevo órgano en la Administración parlamentaria en cuya Dirección General de Relaciones Exteriores se instituye una unidad especifica sobre escrutinio del PS), España (Resolución de Mesas Conjuntas de ambas Cámaras sobre procedimiento parlamentario de escrutinio sobre la aplicación del principio de subsidiariedad de 27 de mayo de 2010), Portugal (reforma reglamentaria sobre el procedimiento de escrutinio de 20 de enero de 2010), Dinamarca (reforma reglamentaria de 26 de marzo de 2010 de seguimiento del escrutinio sobre el PS). Otras reformas reglamentarias en curso, en aquella etapa, fueron la austriaca o la irlandesa, que contaban con normas provisionales, en línea con una larga serie de reformas de los países de la UE.

Otros rasgos generales recogidos en el informe de los letrados de la CMUE sobre información europea, además de la alerta temprana, como ejemplo de esta «monitorización» parlamentaria prevista en el art. 12 TUE que reconoce importantes facultades de participación a los Parlamentos nacionales «para contribuir al buen funcionamiento de la Unión», son:

- Una actividad selectiva en el objeto de monitorización que suele ceñirse a las propuestas legislativas. 
- Predominio de las comisiones de asuntos europeos o, en su defecto, de las de relaciones exteriores o incluso en algún caso de la biblioteca o unidad de estudios parlamentarios, al menos en el plano de iniciación y preparación, ya que en un 65 por 100 de Cámaras la decisión final le corresponde al Pleno.

- En esta primera fase una elevada mayoría de Estados aún no tenían procedimientos específicos para el escrutinio y aplicaban por analogía procedimientos estándar.

- Siendo una nueva facultad de los Parlamentos nacionales participar en la implementación de las políticas de la Unión en el área de libertad, seguridad y justicia y en la evaluación de actividades de EUROPOL y EUROJUST, solo un pequeño número de Cámaras regionales participaba en estos asuntos.

- La mayoría sí había preparado reglamentación relativa a la participación en los procedimientos de revisión simplificada de los Tratados (las «pasarelas») y las que lo habían hecho solían incorporar el principio de que sus respectivos Gobiernos no apoyen una propuesta en el Consejo para usar pasarelas, a menos que cuenten con el previo consentimiento del Parlamento.

- En casi todos los Parlamentos bicamerales las Cámaras deciden individualmente.

- En lo atinente a la interposición del recurso de anulación ante el Tribunal de Justicia de las CE por infracción del PS (art. 8 del Protocolo), menos de la mitad de las Cámaras habían adoptado procedimientos para tal efecto en un primer momento.

- Por último, en lo referente a la cooperación interparlamentaria entre los Parlamentos nacionales y el Parlamento Europeo, cada Cámara participa con delegaciones permanentes ante el Parlamento y el IPEX, así como en el campo funcionarial en el Centro Europeo para la Investigación y Documentación Parlamentaria (ECPRD), o reforzando el principio de cooperación interparlamentaria entre comisiones homologas para tratar asuntos concernientes a la UE y los Estados miembros. Así, ha venido con posterioridad desarrollándose en materias como PNR (passenger name record) o normativa común de asilo y refugio, o el reciente GDPR (nuevo Reglamento europeo de protección de datos), como ejemplos que están en la agenda de los últimos años como consecuencia de este principio de cooperación interparlamentaria surgido tras el Tratado de Lisboa. 
En estas tareas de «monitorización» de los documentos europeos, los criterios mas relevantes para la elección son: el interés nacional (Bulgaria, Hungría, Chipre, Luxemburgo, Polonia o Bélgica), la relevancia de los asuntos (Reino Unido o Dinamarca) o el interés de los Lander (RFA). Siendo muy amplia la gama de órganos envueltos en estas materias desde el Pleno (Rumania), el presidente (Polonia), las Comisiones de Asuntos Europeos (Grecia, Reino Unido, Portugal, Polonia, etc.), Comisiones especializadas (Holanda o Bulgaria), la Mesa y Portavoces de la Comisión Conjunta para asuntos UE (España), los portavoces con los presidentes de las Comisiones (Eslovenia), etc. A destacar, en casi todos los casos, el relevante papel de información del Gobierno, salvo en algún sistema presidencialista como Chipre, y el papel fundamental de los servicios parlamentarios, usualmente de estudios europeos y en algunos casos internacionales.

En esta primera fase, en treinta y tres Parlamentos de los cuarenta había procedimientos específicos para llevar a cabo el escrutinio con hasta veintisiete procedimientos diferentes, de los cuales en trece casos la decisión final corresponde al Pleno, en siete solo interviene el Pleno cuando el órgano preparatorio consideraba que se daba una quiebra en el principio de subsidiariedad, y en cinco casos más el Pleno solo intervenía con carácter opcional. En cinco Cámaras la decisión sobre la subsidiariedad era tomada por comisiones u otros órganos especializados en asuntos europeos.

\section{LA EXPERIENCIA ESPAÑOLA ${ }^{1}$}

El Parlamento español (Cortes Generales) ha sido uno de los primeros en abordar la cuestión del procedimiento del control del principio de subsidiariedad previsto en el Tratado de Lisboa, que, en nuestro caso, ha sido confiado básicamente a la Comisión Mixta para la UE (en adelante, CMUE).

¿Cuáles son los antecedentes de la actual situación y el alcance de la participación parlamentaria de las Cortes Generales, conforme a lo dispuesto en el art. 12.b) del TUE y a la normativa interna en esa contribución activa al «buen funcionamiento de la Unión, para lo cual [...] b) velarán para que se respete el principio de subsidiariedad de conformidad con los pro-

\footnotetext{
${ }^{1}$ Elaborado con información de los letrados de las Cortes Generales en la CMUE, especialmente de I. Carbajal Iranzo.
} 
cedimientos establecidos en el protocolo sobre la aplicación de los principios de subsidiariedad y proporcionalidad»?

Antecedentes: la Ley 8/1994, de 19 de mayo, por la que se regula la Comisión Mixta para la UE, hacía referencia en su Exposición de Motivos a la entrada en vigor del TUE el 1 de noviembre de 1993 y a la previsión contenida en dicho Tratado acerca de que los Parlamentos nacionales dispusieran de las propuestas legislativas de la Comisión con antelación suficiente para información o examen, a cuyo fin la anterior regulación de la Comisión Mixta para las Comunidades Europeas contenida en la Ley 47/1985, de bases de delegación al Gobierno para la aplicación del Derecho de las Comunidades Europeas, había quedado obsoleta y ello requería su sustitución por la nueva ley que regulaba la composición y fines de este órgano de las Cortes Generales especializado en asuntos europeos que pasaba a denominarse «Comisión Mixta para la Unión Europea».

La CMUE, órgano con sede en el Congreso de los Diputados donde se ubica su secretaría y asesoramiento, contaba en un primer momento (IX Legislatura) con 43 miembros, 24 diputados y 19 senadores, de los cuales 19 corresponden al Grupo Parlamentario Socialista y 19 al Popular, y uno por cada uno de los otros grupos parlamentarios. Y venía siendo un precedente que esta comisión fuera presidida por un miembro del principal grupo parlamentario de la oposición. En la IX Legislatura, un secretario era senador y de los siete portavoces, tres eran senadores.

En 2005 se constituyó en la CMUE un grupo de trabajo sobre el sistema de alerta temprana, cuyo informe fue aprobado por unanimidad en la última sesión de la Comisión Mixta de la VIII Legislatura el 18 de diciembre de 2007 (BOCG, 4 de enero de 2008).

La CMUE acordó aprobar unos criterios para la realización de unos ensayos piloto sobre el control de subsidiariedad (BOCG, Serie A, de 16 de abril de 2009); acuerdo que es el fundamento de la regulación posterior y que permitió que la CMUE participara en los dos últimos ensayos piloto de la COSAC sobre la aplicación de la alerta temprana el 23 de septiembre de 2009 [Resolución de la CMUE sobre la propuesta de decisión-marco del Consejo sobre derecho a interpretación y traducción en los procesos penales (BOCG, de 23 de septiembre de 2009)] y el 22 de diciembre de 2009 [Resolución relativa a la Propuesta de Reglamento sobre jurisdicción y legislación aplicable, y reconocimiento de decisiones y medidas administrativas en materia de sucesiones y donaciones (BOCG de la misma fecha)]. En ambos casos se concluía con el reconocimiento del cumplimiento del PS en ambas iniciativas europeas. 
Ya en la IX Legislatura se constituyó en la CMUE una ponencia de estudio sobre los efectos para las Cortes Generales del Tratado de Lisboa que, sobre la base de anteriores acuerdos, preparó un borrador de norma para adaptar la Ley de 1994. El texto fue aprobado por la Comisión Mixta el 24 de marzo de 2009 y sirvió de base a la Proposición de Ley de los Grupos Parlamentarios Socialista, Popular, CiU, Vasco y Mixto.

La Proposición de Ley de cinco grupos parlamentarios se presentó en el registro del Congreso de los Diputados el 16 de octubre de 2009, fue tomada en consideración por el Pleno el 24 de noviembre y aprobada por el procedimiento de urgencia y lectura única el 3 de diciembre de 2009. El Senado aprobó, sin modificaciones y por igual procedimiento, la Proposición en el Pleno de 16 de diciembre de 2009.

La Ley 24/2009, de 22 de diciembre (publicada en el BOE el 23 de diciembre de 2009), añade un apartado nuevo $j$ ) al art. 3 en el que se recoge la competencia de la CMUE para emitir en nombre de las Cortes Generales, con arreglo a la normativa europea aplicable, dictamen motivado sobre la vulneración del principio de subsidiariedad. Mientras que los arts. 5 y 6 regulan el procedimiento de adopción del dictamen.

Posteriormente, mediante Resolución de Mesas Conjuntas de 27 de mayo de 2010 (BOCG de 8 de junio de 2010) se reguló el procedimiento estrictamente parlamentario en desarrollo de la Ley 24/2009, en ejercicio del principio de autonomía normativa de las Cámaras y de las Cortes Generales previsto en el art. $72 \mathrm{CE}$.

Los rasgos más singulares de la actuación en materia de control de la aplicación del PS por las iniciativas legislativas de la UE en las Cortes Generales son:

- Cabe la posibilidad de que la CMUE no tenga la última palabra en el procedimiento de escrutinio de la aplicación del PS, pues la nueva Ley prevé que los Plenos de una u otra Cámara avoquen el debate y votación del dictamen.

- Se contempla (art. 6) el envío de las iniciativas a los parlamentos regionales «sin prejuzgar la existencia de competencias autonómicas» que dispondrán de un plazo de cuatro semanas para remitir a la CMUE su dictamen motivado; dictámenes que se unirán al que, en su caso, elabore la CMUE.

- Se prevé, asimismo [art. 3.j)], la petición por la CMUE de información al Gobierno que deberá remitirla en el plazo máximo de dos semanas acompañada, en su caso, de documentación; en la prácti- 
ca, sin embargo, solo se pide esta información si, y a la vez que, se designa ponente cuando se decide crear una ponencia para valorar la vulneración.

El procedimiento a grandes rasgos consiste en lo siguiente:

- Seguimiento sistemático de las iniciativas por la Mesa de Portavoces de la CMUE.

- Los proyectos de actos legislativos se remiten por correo electrónico a los Parlamentos nacionales a una dirección única de correo electrónico en cada Cámara.

- Los proyectos deben enviarse motivados sobre los PS y PP, y con una ficha en formato electrónico que permita evaluar el cumplimiento de tales. Se reciben en español, inglés y francés; esto último para contrastar con otras Cámaras, si fuera necesario.

- Recibida la iniciativa se envía a los Parlamentos autonómicos también por correo electrónico en la mayoría de los casos el mismo día de la recepción, abriéndose el plazo de cuatro semanas para el informe de la Asamblea autonómica. Una vez recibidos, el presidente de la CMUE los remite al presidente del Congreso y al presidente del Senado y se incluyen en el índice de documentos para la siguiente sesión de Mesa y Portavoces.

La interpretación de la mayoría de Parlamentos autonómicos es que solo enviarán dictámenes si hay disconformidad con la aplicación del PS. Lo cierto es que de las aproximadamente noventa y ocho iniciativas remitidas desde abril de 2010 no ha habido dictámenes autonómicos de disconformidad, excepto en un caso del Parlamento vasco sobre policías integrales.

En cuanto al órgano autonómico competente (comisión sectorial o de asuntos europeos) dependerá del correspondiente reglamento del Parlamento autonómico.

Importa destacar que los dictámenes de los Parlamentos autonómicos no son vinculantes para la CMUE, pero si hubiera dictamen de disconformidad se incluirían entre la documentación a remitir.

- La secretaría de la CMUE incorpora la documentación a la base de datos de la CMUE. En esta base están todas las iniciativas agrupadas por iniciativas europeas $\mathbf{y}$ toda la documentación que generan (informes del Gobierno, autonómicos, etc., en el caso de la alerta temprana), así como todos los plazos (dies a quo, a quem, etc.) y fechas. Un índice de esta base se entrega a los miembros de la Mesa y Portavoces todos los lunes, incluyendo todos los documentos desde la última reunión hasta las veinte horas del viernes anterior. 
- Un órgano esencial en la marcha de la actividad de la CMUE es la Mesa y Portavoces, un total de doce parlamentarios que, junto con los letrados de la Comisión, efectúan el seguimiento de todas las iniciativas. La Mesa y Portavoces deciden mediante la aplicación del voto ponderado de los miembros con que cada grupo parlamentario cuenta en la CMUE. Este órgano se reúne al menos dos veces al mes (art. 7 RMC). Y durante los periodos intersesiones solo se reunirán si se convoca sesión extraordinaria a petición del Gobierno, de la Diputación Permanente o de la mayoría absoluta de miembros de cualquiera de las Cámaras. Mientras que en periodos de disolución la CMUE queda también disuelta.

- Ante cada proyecto de acto legislativo recibido, la Mesa y Portavoces de la CMUE pueden hacer:

1. Tomar conocimiento del proyecto. Lo que equivale a una conclusión provisional del procedimiento:

a) Mientras no finalice el plazo de cuatro semanas (art. 8, apartado 1, RMC) durante el cual dos grupos parlamentarios o un quinto de los miembros de la CMUE están facultados para iniciar el procedimiento.

b) Mientras la Mesa y Portavoces no decidan, incluso después del plazo de cuatro semanas, iniciar una Ponencia (por ejemplo, por un informe motivado autonómico).

2. Designar una ponencia para que elabore una propuesta de dictamen motivado; criterio que, una vez adoptado, le corresponderá ejecutar solo a la Mesa. La ponencia podría ser individual o colectiva, pero la práctica esta siendo la designación de ponencias individuales que habitualmente recaen en un parlamentario de uno de los dos grupos más numerosos en las Cortes, aunque ha habido un ponente también de CiU. Este ha sido el procedimiento habitual hasta la fecha.

- La Mesa y Portavoces pueden solicitar en el inicio del procedimiento una informe «sucinto» al Gobierno sobre el contenido sustancial de la iniciativa acompañado de documentación; ahora bien, en la práctica solo se pide informe cuando se designa ponencia.

- Asimismo, si la Mesa lo acuerda, cabe citar al Gobierno, autoridades y funcionarios a comparecer con carácter informativo, complementario o alternativo en caso de urgencia extrema ante la CMUE o ante la ponencia. Si bien hasta el momento no ha habido ninguna comparecencia. 
- El ponente analiza la iniciativa, aplica el test de subsidiariedad y propone un proyecto de dictamen motivado a la CMUE cuando estime que la iniciativa no se ajusta al PS, mientras que en caso de no apreciar vulneración hará un «informe».

- La CMUE, recibida la propuesta del ponente, la distribuirá y abrirá plazo no inferior a cinco días hábiles para la presentación de «propuestas alternativas y de enmiendas, así como solicitudes de avocación al Pleno».

Hasta la fecha no ha habido ni propuestas alternativas ni enmiendas. Siendo el debate igual al de las PNL (autor, enmendantes, no enmendantes y autor), pudiendo la Mesa acordar que comparezca el Gobierno o funcionarios para explicar su posición. Hasta la fecha el ponente expone, luego intervienen los grupos parlamentarios (caben enmiendas transaccionales que requieren que ningún grupo se oponga a su tramitación, al igual que en Pleno) y correcciones. Acabado el debate, el proponente indica qué enmiendas se aceptan y se votaría este texto. Si hubiera alternativas se votarían sucesivamente y, de aprobarse una, acabaría el debate. Por hipótesis, cabría también votar por partes si no hay reparo de los autores.

- El régimen de sesiones públicas es el general y, posteriormente, se publican en el BOCG.

- Por conducto de los presidentes, se remiten al Gobierno y al presidente del Parlamento Europeo, del Consejo y de la Comisión (que ha comunicado su criterio amplio en orden a la recepción), y se publican en el IPEX.

También se mandan al letrado representante permanente de las Cortes Generales en la UE para su distribución a los representantes de otros países en la red de enlace de la que proviene una información utilísima de lo hecho por la CMUE española y viceversa, y se publican en el IPEX.

- Si la iniciación del procedimiento proviene de dos grupos parlamentarios o un quinto de los miembros, la petición irá acompañada de la propuesta a la que también se incorporarán propuestas alternativas, enmiendas y solicitudes de avocación.

- En caso de avocación por el Pleno de la aprobación final de la propuesta, una vez aprobado el dictamen por la CMUE, el presidente de la CMUE lo elevará a los presidentes de las Cámaras quienes abrirán plazo de dos días hábiles para presentación de propuestas alternativas o enmiendas.

A destacar que la experiencia en España en los primeros meses de práctica (de abril de 2010 a febrero de 2011) sobre las noventa y ocho iniciativas remitidas por la UE, de ellas, la CMUE ha aprobado en torno a un 
20 por 100 de informes, ninguno de los cuales ha detectado afectación del principio de subsidiariedad o de proporcionalidad, habiendo una media decena de informes pendientes. Y como Estado compuesto, las Asambleas autonómicas han remitido hasta la fecha a la CMUE 443 escritos acerca de las iniciativas remitidas, todos ellos de conformidad excepto uno. Queda pendiente analizar si la evolución de este asunto ha consolidado los precedentes y cuál es el alcance de la participación de las Cortes Generales en este punto, como test sobre la eficacia de este nuevo sistema de control parlamentario sobre iniciativas legislativas de la UE. 